Early Intervention in Psychiatry - Manuscript Submission - Brief Report

\title{
Examination of cultural competence in service providers in an early intervention programme for psychosis in Montreal, Quebec: Perspectives of service users and treatment providers ${ }^{+}$
}

\author{
Shruthi Venkataraman ${ }^{1}$; Gerald Jordan²; Megan A Pope ${ }^{1}$; Srividya N Iyer ${ }^{1,2,3}$ \\ ${ }^{1}$ Prevention and Early Intervention Program for Psychosis (PEPP-Montreal), Douglas Mental Health \\ University Institute, Montreal, Quebec, Canada \\ ${ }^{2}$ Department of Psychiatry, McGill University, Montreal, Quebec, Canada \\ ${ }^{3}$ ACCESS Open Minds, Douglas Mental Health University Institute, Montreal, Quebec, Canada
}

Correspondence:

Srividya Iyer, ACCESS Open Minds/Esprits Ouverts, Douglas Mental Health University Institute, 6625 Boulevard LaSalle, ACCESS Pavilion, Verdun, Montreal, Quebec, H4H1R3, Canada

Email: srividya.iyer@mcgill.ca

\section{Funding information}

Srividya Iyer received support from Canadian Institutes of Health Research (CIHR) and Fonds de Recherche du Québec-Santé (FRQS) salary awards. Megan Pope and Gerald Jordan received support from FRQS graduate training awards. Gerald Jordan is currently supported by a ClHR doctoral training award.

\section{ACKNOWLEDGEMENTS}

No funding was received to conduct this study. The senior author (Iyer) is supported by a Junior 1 salary award from the Fonds de recherche du Québec - Santé (FRQS). Pope and Jordan were supported by graduate scholarship awards from FRQS and Canadian Institutes of Health Research (CIHR). None of the authors have any other pertinent personal affiliations or financial interests to declare. The authors would like to thank Dr. Rukhsana Ahmed at the University of Ottawa for permitting the use of her scale to assess cultural competence among physicians. We also thank service users and service providers at the Prevention and Early Intervention Programme for Psychosis at the Douglas Mental Health University Institute for their participation in this study.

TThis paper was presented as an Oral Presentation at the 3rd International Conference on Youth Mental Health, Montreal, Canada (October 8-10, 2015) and as a Poster Presentation at the 7th International Conference on Schizophrenia, Chennai, India (September 8-10, 2016). 


\begin{abstract}
Aim: To better understand cultural competence in early intervention for psychosis, we compared service users' and service providers' perceptions of the importance of providers being culturally competent and attentive to aspects of culture.

Methods: At a Canadian early intervention programme, a validated scale was adapted to assess service user $(N=51)$ and provider $(N=30)$ perceptions of service providers' cultural competence, and the importance accorded thereto.

Results: Analyses of variance revealed that the importance of service providers being culturally competent was rated highest by service providers, followed by visible minority service users, followed by white service users. Providers rated themselves as being more interested in knowing service users' culture than service users perceived them to be.

Conclusions: Service users accorded less import to service providers' cultural competence than providers themselves, owing possibly to varied socialization. A mismatch in users' and providers' views on providers' efforts to know their users' cultures may influence mental healthcare outcomes.
\end{abstract}

\title{
KEYWORDS
}

Cultural competence, culture, early intervention, psychosis, youth mental health 


\section{1 | INTRODUCTION}

As the "house of difference," (XXXX, 2002) Canada prides its commitment to multiculturalism. This commitment and the country's racial, cultural and linguistic diversity make the preservation of Canadians' ethnocultural identities an imperative. For instance, Canada's Indigenous peoples have posited the restoration of their culture as a means to alleviating their suffering (Chandler \& Lalonde, 1998). Preserving and continuing to identify with one's cultural group/framework enhances resilience and predicts better mental well-being (Burgess, Johnston, Bowman, \& Whitehead, 2005).

The cultures of service users and treatment providers can shape every aspect of a clinical encounter, including patients' experience and expression of illness and the course and outcome of its treatment (Angel \& Thoits, 1987; Kirmayer, 2001; López \& Guarnaccia, 2000; Miller et al., 2006). Research consistently shows that vulnerable populations have reduced access to healthcare, receive lower-quality care, are likelier to disengage from care, and experience poorer outcomes (Shah, Gunraj, \& Hux, 2003; Tonelli, 2004; Zheng, Poon, \& Verma, 2013). Fostering cultural competence in clinicians has been suggested as a way to redress this situation for people from ethnocultural minorities (Brach \& Fraser-irector, 2000).

In mental healthcare, the construct of culture is even more important, given how closely intertwined it is with the construct of mind (Sue, Zane, Nagayama Hall \& Berger, 2009) and how the ill bear the added burden of stigma (Wahl, 1999).

At the earliest stages of serious mental illnesses like psychosis, patients are often younger, living with families and grappling with identity formation. Cultural competence is therefore, particularly important for the providers of early intervention services if these services are to engage and serve youths with psychosis from varied backgrounds.

Little research has focused on cultural competence in the context of early intervention for psychosis. Seeking to address this gap, the primary aims of our study were to examine and compare:

1. Visible minority service users', white service users' and service providers' perceptions regarding the importance of the cultural competence of providers

2. Visible minority service users', white service users' and service providers' ratings of the attentiveness of providers to issues of culture, religion, etc.

We specifically explored differences between the opinions of visible minority and white service users, considering that racial identity has been shown to affect patients' perceptions of cultural competence in healthcare providers (Johnson, Saha, Arbelaez, Beach \& Cooper, 2004; Pomales, Clairborn, \& LaFromboise, 1986). 


\section{2 | METHODS}

This study was conducted at the Prevention and Early Intervention Programme for Psychosis (PEPP) in Montreal, Quebec, Canada, which serves youths (aged 14-35) with first-episode psychosis. Each PEPP client is closely followed by a case manager and a psychiatrist and receives a range of psychosocial and medical services (Iyer, Jordan, MacDonald, Joober, \& Malla, 2015).

Our study used a validated scale measuring patients' perceptions of physicians' cultural competence (Ahmed, 2007), with minor adaptations made with its developer's permission. Modifications included creating a version for service providers; adding a section on "Importance" and translating both versions into French.

Our adapted scale included 16 domains of culture (e.g., racial background, religious beliefs/practices, etc.; Table 2). Each domain was rated on two 5-point Likert scales, one assessing competence (e.g. "My treatment team wants to know about my nationality" in the service user version or "I want to know about the nationality of my clients" in the service provider version) and the other assessing importance (e.g. "How important is it for you that your treatment team knows about your nationality?" in the service user version or "How important is it for you to know about the nationality of your clients?" in the service provider version). As conceptualized in the original scale, wanting to know about/attentiveness to 'aspects of service users' culture were a proxy for the service provider's cultural competence.

We administered the scale and a socio-demographic questionnaire to a convenience sample of service users and providers. Statistics Canada classifications (Visible minority-National Household Survery (NHS) Dictionary, 2016) were used to group individuals as being visible minority or white. The relevant ethics board approved this study and all service users surveyed consented to participating in research.

\section{3 | ANALYSIS}

Based on service users' and service providers' ratings of competence and importance, we calculated mean scores across all 16 domains of culture for each participant. We compared service providers', visible minority service users' and white service users' mean ratings of competence and importance via two sets of three way between groups analyses of variance.

\section{4 | RESULTS}

Five of the 56 service users approached refused to participate in the study. All service providers approached agreed to participate. Compared to service providers $(N=51)$, service users $(N=30)$ were likelier to be male, younger, less educated, poorer and from a visible minority (Table 1). Table 2 presents descriptive statistics for importance and competence ratings across the 16 domains 
provided by white service users, service users from visible minority backgrounds and service providers.

Figure 1 graphs the findings of our main analyses. Compared to white service users $(n=21$, $M=2.14, S D=.66)$, those from visible minority backgrounds $(n=20)$ rated as more important $(M=$ $2.89, \mathrm{SD}=.87$ ) that service providers know about aspects of their background (e.g, gender, race, religion, language, cultural background etc.). Yet, both white and visible minority service users rated the importance of cultural competency in service providers lower than service providers themselves $\operatorname{did}(n=29, M=3.73, S D=.81)[F(2,67)=25.22 ; \mathrm{P}=.001,95 \% \mathrm{Cl} 1.03$ to $2.14,95 \% \mathrm{Cl} .28$ to 1.40$]$.

Furthermore, service providers $(n=28, M=4.02, S D=.41)$ rated themselves as being more interested in knowing their patients' background (e.g, gender, race, religion, language, cultural background, etc.) than both visible minority $(n=23, M=3.11, S D=.78)$ and white service users perceived them to be $(n=22, M=3.13, S D=1.00)$. There was no difference between white service users and those from visible minority backgrounds in how culturally competent they perceived service providers to be.

\section{5 | DISCUSSION}

Our study addresses an important gap in the understanding of service user and service provider perceptions of cultural competence in the context of early intervention for psychosis.

Service providers thought it more important to know aspects of service users' culture than did service users. Service providers may have come to value being aware of patients' cultural backgrounds because of training, exposure to pertinent research and reflective practice, all of which emphasize cultural competence. Given the emphasis placed on service engagement in early intervention services for psychosis (lyer \& Malla, 2014; lyer et al., 2015; McGorry, Killackey, \& Yung, 2008), service providers may also view showing an interest in their patients' culture and background as a means of engaging them. Moreover, it cannot be discounted that attesting to cultural competence may also be socially desirable among service providers.

In contrast, service users may not have rated service providers' cultural competence as being very important because they viewed other skills and functions (e.g, instrumental support) as being more important. Alternatively, if service users are broadly satisfied with the quality of their care as they tend to be in early intervention services (Iyer \& Malla, 2014; Singh, 2010), they may accord less import to a narrower dimension of care like the cultural competence of service providers.

The Quebec context, where this study is based, raises its own particularities. Since the Quiet Revolution (McRoberts, 1988), Quebec has positioned itself as a secular society. Public spaces such as hospitals and schools are permeated by the idea that people should be served the same way 
regardless of their cultural backgrounds (Koussens, 2009; Rukavina, 2015; Selby, 2014). In the extreme, this idea has fomented troubling discourse on the limits of "reasonable accommodation for the other"(Bouchard, 2008). Quebec's arguably greater focus on integration rather than multiculturalism may subtly discourage expressions of diverse ethnocultural identities and expectations that such diversity be acknowledged (Wong, 2011). In this milieu, service users may not be socialized into prioritizing service providers' cultural competence.

Service providers reported enquiring about service users' cultural backgrounds much more than service users reported them doing. This mismatch of perceptions between service users and providers may influence mental healthcare delivery and outcomes, potentially impeding service engagement. Our findings suggest that service providers ought not only to make efforts to know about service users' backgrounds, but also to be sensitive to how service users perceive these efforts.

With the benefit of many interactions with numerous patients, service providers can base their self-ratings on their most positive clinical encounters. In contrast, service users rate only their current treatment providers. Service providers may also be rating themselves higher because they often reasonably assume or surmise things about patients' cultural backgrounds, whereas service users may be rating them lower because service providers may not explicitly ask about their backgrounds. Moreover, our finding of a mismatch between service provider and service user ratings is consistent with a similar finding that clinicians often perceive a stronger therapeutic alliance with their patients than their patients do (Ogrodniczuk, Piper, Joyce, \& McCallum, 2000).

Because their cultural backgrounds differed from those of the majority, visible minority service users may have felt unable to assume foreknowledge thereof among service providers and may have therefore thought it more important for service providers to know aspects of their backgrounds.

\section{6 | CONCLUSION}

Given that early intervention services in various parts of the world serve increasingly diverse populations, the cultural competence of service providers and the perceptions thereof can have significant implications for providing better, more engaging services. In this context, our study makes an important contribution.

Among our study's limitations is its relatively small sample that is not fully representative. Nonetheless, our high survey response rate (91\%) suggests that our sample is at least not biased in favour of highly engaged clients. Our assessment of cultural competence was limited to the desire to know aspects of another person's background. Finally, estimating different component scores/factors could have permitted a more refined interpretation based on between-group 
differences in specific subdomains of cultural importance and competence. Our small samples size precluded factor analysis of our adapted scale. We intend to undertake such an analysis in the future.

Future qualitative research can unpack various stakeholders' perspectives on the construct of culture in the early intervention service context. Such work should examine perceptions at both the individual levels of the young service user or provider and the systemic level of healthcare institutions and societies. 


\section{REFERENCES}

Ahmed, R. (2007). Assessing the role of cultural differences on health care receivers' perceptions of health care providers' cultural competence in health care interactions. Doctoral dissertation, Ohio University.

Angel, R., \& Thoits, P. (1987). The impact of culture on the cognitive structure of illness. Culture, Medicine, and Psychiatry, 11(4), 465-494.

Bouchard, G., \& Taylor, C. (2008). Building the future, a time for reconciliation: Report. Commission de consultation sur les pratiques d'accomodement reliées aux différences culturelles. Québec. Gouvernement du Québec. 310 p.

Brach, C., \& Fraserirector, I. (2000). Can cultural competency reduce racial and ethnic health disparities? A review and conceptual model. Medical Care Research and Review, 57(4 suppl), 181-217.

Burgess, C. P., Johnston, F. H., Bowman, D. M. J. S., \& Whitehead, P. J. (2005). Healthy country: Healthy people? Exploring the health benefits of Indigenous natural resource management. Australian and New Zealand Journal of Public Health, 29(2), 117-122.

Chandler, M. J., \& Lalonde, C. (1998). Cultural continuity as a hedge against suicide in Canada's first nations. Transcultural Psychiatry, 35(2), 191-219.

Iyer, S., Jordan, G., MacDonald, K., Joober, R., \& Malla, A. (2015). Early intervention for psychosis. The Journal of Nervous and Mental Disease, 203(5), 356-364.

Iyer, S. N., \& Malla, A. K. (2014). Early intervention in psychosis: Concepts, current knowledge and future directions/Intervention precoce pour la psychose: Concepts, connaissances actuelles et orientations futures. Santé Mentale au Québec, 39(2), 201-230.

Johnson, R. L., Saha, S., Arbelaez, J. J., Beach, M. C., \& Cooper, L. A. (2004). Racial and ethnic differences in patient perceptions of bias and cultural competence in health care. Journal of General Internal Medicine, 19(2), 101-110.

Kirmayer, L. J. (2001). Cultural variations in the clinical presentation of depression and anxiety: Implications for diagnosis and treatment. The Journal of Clinical Psychiatry, 62, 22-30. 
Koussens, D. (2009). Neutrality of the state and regulation of religious symbols in schools in Quebec and France. Sociology Compass, 56(2), 202-213.

López, S. R., \& Guarnaccia, P. J. (2000). Cultural psychopathology: Uncovering the social world of mental illness. Annual Review of Psychology, 51(1), 571-598.

Mackey, E. (2002). The house of difference: Cultural politics and national identity in Canada (Vol. 23). University of Toronto Press.

McGorry, P. D., Killackey, E., \& Yung, A. (2008). Early intervention in psychosis: Concepts, evidence and future directions. World Psychiatry, 7(3), 148-156.

McRoberts, K. (1988). Quebec: Social change and political crisis. Toronto, Ont: McClelland and Stewart Limited.

Miller, C. L., Spittal, P. M., Wood, E., Chan, K., Schechter, M. T., Montaner, J. S. G., \& Hogg, R. S. (2006). Inadequacies in antiretroviral therapy use among Aboriginal and other Canadian populations. AIDS Care, 18(8), 968-976.

Ogrodniczuk, J. S., Piper, W. E., Joyce, A. S., \& McCallum, M. (2000). Original research-Different perspectives of the therapeutic alliance and therapist technique in 2 forms of dynamically oriented psychotherapy. Canadian Journal of Psychiatry, 45(5), 452-458.

Pomales, J., Claiborn, C. D., \& LaFromboise, T. D. (1986). Effects of Black students' racial identity on perceptions of White counselors varying in cultural sensitivity. Journal of Counseling Psychology, 33(1), 57.

Rukavina S. 2015. Quebec judge wouldn't hear case of woman wearing hijab. CBC News. Retrieved from http://www.cbc.ca/news/canada/montreal/quebec-judge-wouldn-t-hear-case-of-womanwearing-hijab-1.2974282

Selby, J. A. (2014). Un/veiling women's bodies: Secularism and sexuality in full-face veil prohibitions in France and Quebec. Studies in Religion/Sciences Religieuses, 43(3), 439-466. 
Shah, B. R., Gunraj, N., \& Hux, J. E. (2003). Markers of Access to and quality of primary care for Aboriginal People in Ontario, Canada. American Journal of Public Health, 93(5), 798-802.

Singh, S. P. (2010). Early intervention in psychosis. The British Journal of Psychiatry,196(5), 343-345.

Sue, S., Zane, N., Nagayama Hall, G. C., \& Berger, L. K. (2009). The case for cultural competency in psychotherapeutic interventions. Annual Review of Psychology, 60(1), 525-548.

Tonelli, M. (2004). Death and renal transplantation among Aboriginal people undergoing dialysis. Canadian Medical Association Journal, 171(6), 577-582.

Visible minority-National Household Survey (NHS) Dictionary. 2016. Www12.statcan.gc.ca. Retrieved from https://www12.statcan.gc.ca/nhs-enm/2011/ref/dict/pop127-eng.cfm

Wahl, O. F. (1999). Mental health consumers' experience of stigma. Schizophrenia Bulletin, 25(3), 467-478.

Wong, A. (2011). The disquieting revolution: A genealogy of reason and racism in the Québec press. Global Media Journal, 4(1), 145.

Zheng, S., Poon, L. Y., \& Verma, S. (2013). Rate and predictors of service disengagement among patients with first-episode psychosis. Psychiatric Services, 64(8), 812-815. 
TABLE 1 Demographic characteristics of service users and service providers

\begin{tabular}{|c|c|c|c|}
\hline & Service Users;n (\%) & Service providers; $\mathrm{n}(\%)$ & $X^{2} / F$ \\
\hline Total N & 51 & 30 & - \\
\hline \multirow[t]{2}{*}{ Average Age } & $M=25.70$ & $M=38.67$ & $47.55 * * *$ \\
\hline & $(S D=6.08,95 \% \mathrm{Cl} 23.97$ to 27.43$)$ & $(\mathrm{SD}=8.664,95 \% \mathrm{Cl} 34.36$ to 42.97$)$ & \\
\hline Sex & & & $4.67^{*}$ \\
\hline Male & $33(64.7 \%)$ & $12(40 \%)$ & - \\
\hline Education Level & & & $28.03 * * *$ \\
\hline High school or lower & $30(58.8 \%)$ & 0 & - \\
\hline $\begin{array}{l}\text { Advanced Degrees } \\
\text { (Diploma, Bachelor's, } \\
\text { Master's, Doctoral } \\
\text { etc.) }\end{array}$ & $21(41.2 \%)$ & $30(100 \%)$ & - \\
\hline Visible Minority & $25(50 \%)$ & $8(26.7 \%)$ & 4.21* \\
\hline Languages & & & 0.01 \\
\hline $\begin{array}{l}\text { English, French or } \\
\text { both }\end{array}$ & $23(45.1 \%)$ & $13(46.4 \%)$ & - \\
\hline $\begin{array}{l}\text { Multilingual (another } \\
\text { language besides } \\
\text { English and/or } \\
\text { French) }\end{array}$ & $28(54.9 \%)$ & $15(53.6 \%)$ & - \\
\hline Religion & & & 0.29 \\
\hline $\begin{array}{l}\text { Not Practicing / No } \\
\text { Religious Affiliation }\end{array}$ & $25(73.5 \%)$ & $23(79.3 \%)$ & - \\
\hline $\begin{array}{l}\text { Actively practicing a } \\
\text { religion }\end{array}$ & $9(26.5 \%)$ & $6(20.7 \%)$ & - \\
\hline Yearly Income & & & $19.56 * * *$ \\
\hline Less than $\$ 10,000$ & $19(47.5 \%)$ & 0 & - \\
\hline $\begin{array}{l}\text { Greater than \$ } 10 \text {, } \\
000\end{array}$ & $21(52.5 \%)$ & $30(100 \%)$ & - \\
\hline
\end{tabular}

\footnotetext{
$* \mathrm{P}<.05$

$* * * \mathrm{P}<.001$
} 
TABLE 2 Ratings of importance and competence accorded by white service users, visible minority service users and service providers across 16 domains

\begin{tabular}{|c|c|c|c|c|c|c|}
\hline \multirow[t]{2}{*}{ Domain } & \multicolumn{3}{|c|}{ Importance } & \multicolumn{3}{|c|}{ Competence } \\
\hline & $\begin{array}{c}\text { White } \\
\text { Service } \\
\text { users } \\
\text { M (SD) }\end{array}$ & $\begin{array}{c}\text { Visible } \\
\text { Minority } \\
\text { Service } \\
\text { Users M } \\
\text { (SD) }\end{array}$ & $\begin{array}{c}\text { Service } \\
\text { providers }\end{array}$ & $\begin{array}{c}\text { White } \\
\text { Service } \\
\text { users } \\
\text { M (SD) }\end{array}$ & $\begin{array}{c}\text { Visible } \\
\text { Minority } \\
\text { Service } \\
\text { Users M } \\
\text { (SD) } \\
\end{array}$ & $\begin{array}{c}\text { Service } \\
\text { providers }\end{array}$ \\
\hline Nationality & $1.61(0.89)$ & $2.54(1.44)$ & $3.63(1.07)$ & $2.71(1.37)$ & $2.96(1.24)$ & $4.37(0.81)$ \\
\hline Racial background & $1.61(0.84)$ & $2.50(1.53)$ & $3.53(1.17)$ & $2.79(1.25)$ & $2.64(1.15)$ & $4.10(0.77)$ \\
\hline $\begin{array}{l}\text { Religious } \\
\text { beliefs/practices }\end{array}$ & $2.00(0.95)$ & $2.42(1.32)$ & $3.77(1.04)$ & $3.08(1.28)$ & $2.68(1.07)$ & $4.17(0.80)$ \\
\hline Cultural background & $2.00(1.04)$ & $2.78(1.28)$ & $4.03(0.89)$ & $3.13(1.30)$ & $3.00(1.00)$ & $4.53(0.51)$ \\
\hline Family dynamics & $2.17(0.94)$ & $2.83(1.20)$ & $3.50(1.04)$ & $3.38(1.24)$ & $3.08(1.18)$ & $3.30(0.92)$ \\
\hline Spiritual beliefs & $2.04(0.98)$ & $2.79(1.41)$ & $3.77(1.04)$ & $2.83(1.31)$ & $2.71(1.12)$ & $4.17(0.87)$ \\
\hline Values & $2.65(1.37)$ & $3.43(1.27)$ & $4.10(0.88)$ & $3.25(1.29)$ & $3.57(1.04)$ & $4.53(0.51)$ \\
\hline Food \& dietary habits & $3.08(1.25)$ & $3.36(1.29)$ & $3.37(1.19)$ & $3.79(1.10)$ & $3.96(0.91)$ & $3.45(1.12)$ \\
\hline $\begin{array}{l}\text { Preferred address (Ms., } \\
\text { Mr., etc.) }\end{array}$ & $1.54(0.83)$ & $2.00(1.35)$ & $3.17(1.04)$ & $2.71(1.33)$ & $2.46(1.10)$ & $2.93(1.05)$ \\
\hline Preferred name & $2.04(1.12)$ & $2.17(1.34)$ & $3.50(0.90)$ & $3.13(1.26)$ & $3.13(1.36)$ & $3.73(0.94)$ \\
\hline $\begin{array}{l}\text { Language } \\
\text { preferences/skills }\end{array}$ & $2.17(1.13)$ & $3.00(1.31)$ & $4.00(1.08)$ & $3.26(1.25)$ & $3.50(1.02)$ & $4.47(0.68)$ \\
\hline $\begin{array}{l}\text { Socio-economic } \\
\text { situation/background }\end{array}$ & $2.39(1.20)$ & $2.91(1.27)$ & $4.03(0.93)$ & $3.52(1.08)$ & $3.25(1.03)$ & $4.47(0.68)$ \\
\hline Sexual orientation & $1.78(1.17)$ & $2.52(1.44)$ & $3.27(1.14)$ & $2.67(1.31)$ & $2.75(1.11)$ & $3.70(0.92)$ \\
\hline $\begin{array}{l}\text { Beliefs about mental } \\
\text { illness(es) }\end{array}$ & $2.78(1.48)$ & $3.59(1.33)$ & $4.30(0.99)$ & $3.58(1.32)$ & $3.79(1.06)$ & $4.57(0.73)$ \\
\hline $\begin{array}{l}\text { Strengths/resources } \\
\text { available in } \\
\text { community }\end{array}$ & $2.74(1.36)$ & $3.68(1.32)$ & $4.13(0.86)$ & $3.79(1.14)$ & $3.46(1.06)$ & $4.47(0.57)$ \\
\hline $\begin{array}{l}\text { How gender shapes } \\
\text { life experiences and } \\
\text { experience of } \\
\text { treatment }\end{array}$ & $1.91(0.90)$ & $2.70(1.49)$ & $3.37(1.16)$ & $2.83(1.09)$ & $2.92(1.21)$ & $3.90(0.80)$ \\
\hline Total & $34.51(0.46)$ & $45.22(0.49)$ & $59.47(0.35)$ & $50.45(0.38)$ & $49.86(0.44)$ & $64.86(0.50)$ \\
\hline
\end{tabular}




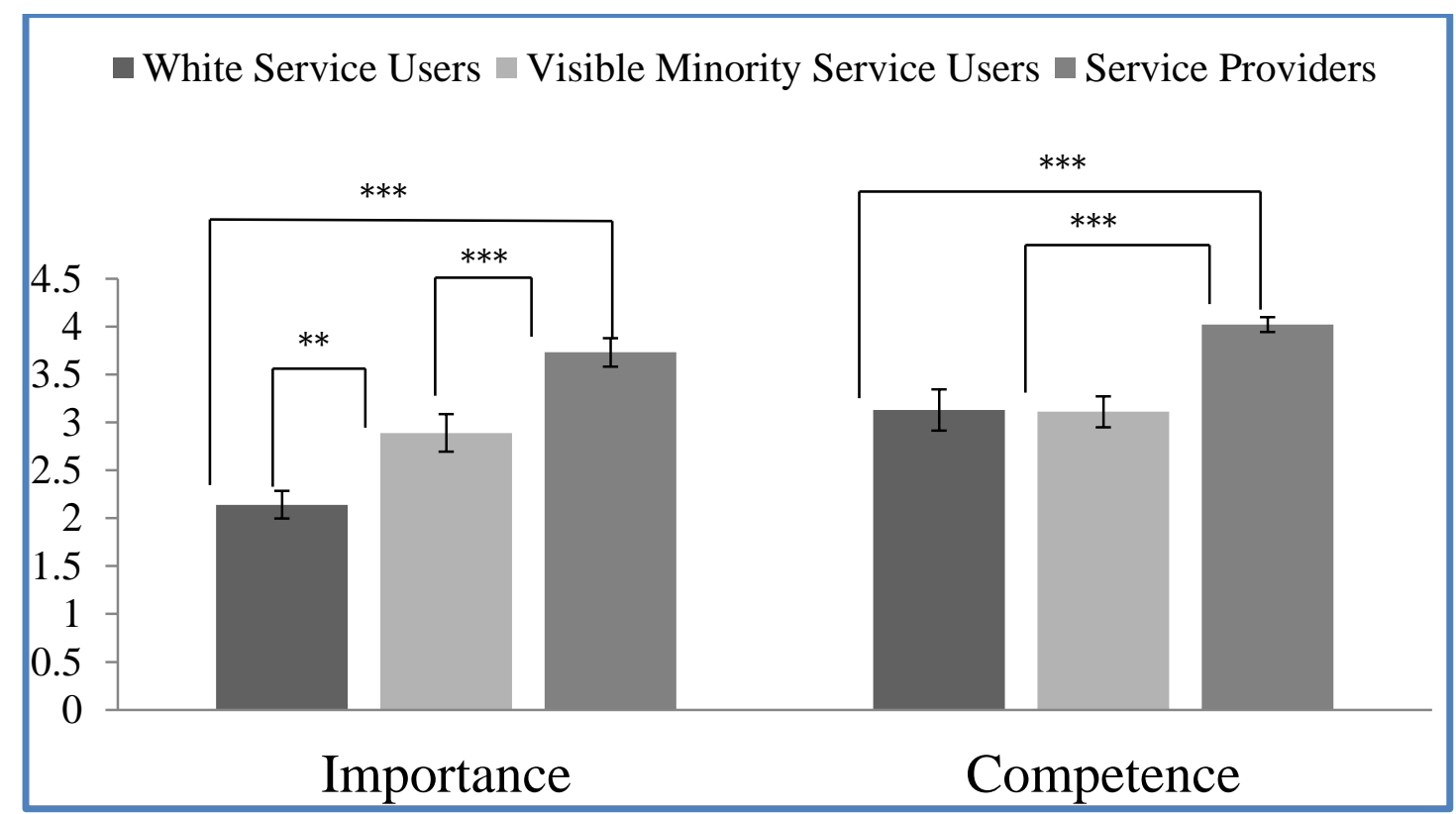

FIGURE 1 The importance of service providers being culturally competent and the cultural competence of service providers, as rated by white service users, visible minority service users and service providers.

$* * * \mathrm{P}<.001 .{ }^{* * \mathrm{P}}<.01$. 